\title{
The Challenges of Creating Sustainable Competitive Advantage in the Banking Industry in Kenya
}

\author{
Dorothy Mghoi Mnjala \\ Masters Student, Jomo Kenyatta University of Agriculture and Technology
}

\begin{abstract}
Players in the banking sector have experienced increased competition over the last few years resulting from increased innovations among the players and new entrants into the market. The only way for banks to remain relevant in their operations is by coming up with competitive advantage that is sustainable. Developing a competitive advantage alone is not enough. Its sustainability is the critical element. For a competitive advantage to attain this aspect, critical thinking and time has to be devoted by the managers concerned. Today, many companies are faced out by competitors since they are unable to create offerings and create sustainable relationships with their customers. The aim of this paper is to analyze how a firm can create a competitive advantage that enables it to be on the forefront in the market and in its general operations. The article as well seeks to give insight into how tangible resources contribute to creation of sustainable competitive advantage thus translating to superior performance. As Business leaders perceive ever-greater links between business performance and their sustainability capabilities, it is clear that the environmental, social and governance issues at the heart of a sustainability strategy are featuring higher on the sustainable competitive advantage. From the discussions, we have seen how sustainability is increasingly seen as an important element in how many companies respond to core strategic challenges. The paper concludes by creating importance of the need of a firm to overcome change inertia and be able to explore new opportunities in the market.
\end{abstract}

Key Words: competitive advantage, sustainable competitive advantage

\section{Introduction}

This paper gives an insight on the creation of sustainable competitive advantage that is important for every firm in order to operate efficiently. It emphasizes on the need for the competency to be valuable, rare and not easy to be duplicated in the same way by other firms. The research study also explains the need for a firm to concentrate on its core competencies and at the same time explore opportunities that are arising so as not to be left behind. Core competencies help an organization to distinguish its products from its rivals as well as to reduce its costs than its competitors and thereby attain a competitive advantage. It helps in creating customer value. Also, core competencies help in creating and developing new goods and services. Core competencies decide the future of the organization. These decide the features and structure of global competitive organization. Core competencies give way to innovations. Using core competencies, new technologies can be developed. They ensure delivery of quality products and services to the clients. The methodology applied in this case study is reading previously published research papers. (Porter, 1980)

\subsection{Competitive advantage and sustained competitive advantage}

A competitive advantage is a value adding strategy that is not being implemented by potential competitors and can hardly be duplicated by competitors. A sustained competitive advantage needs to last for a considerable period of time. Competitors involve both the current firms in operation as well as potential firms that are planning to enter the market in the near future (Baumol Panzar, and Willig 1982). Efforts to duplicate a competitive advantage need to have been rendered futile for a period of time for it to be considered sustainable (Lippman and Rumelt 1984). According to Barney (1991), for a resource to provide a sustainable competitive advantage, it needs to add value to the firm, be unique, perfectly imitable and cannot be substituted by another resource by competing firm.

An organization is said to have competitive advantage if its profitability is higher than the average profitability for all companies in its industry.

\section{Research Gaps}

In the face of rising global competition, technological change and the most serious economic downturn in nearly a century, corporate commitment to the principles of sustainability remains strong throughout the world. Most corporate know how to get at the top but do not know how to stay at the top. Most corporate leaders see sustainability as important to their company's future success. 


\section{Sources of a competitive advantage}

Competitiveness of an organization has become the source of success in the market. A firms internal environment, that is value adding strategies in the value chain and resource capabilities account for its core competencies (Christopher Heywood, Russell Kenley, 2008). A well-designed strategy can help a firm to gain a competitive advantage. This advantage can arise from the following sources:

\subsection{Differentiation}

Differentiation strategy enables a firm to provide goods and services that competitors are not yet offering or are not able to copy. Uniqueness in brand, technology, and products is also a key aspect (Porter 1985) .In Kenya, Equity bank was able to penetrate into the market due to its differentiated customer service and targeting middle and low class group. Banks before were considered to be for the rich and mostly employed people. The banks services were considered the best when it entered the market and thus the bank has up to date created an image in the market as the big bank that gives quality service to its customers. The only thing that made it different from other banks is its differentiated customer service which up to date its competitive advantage.

\subsection{Low cost strategy}

This strategy is based on cost leadership with efficiency and tight cost control (Porter 1985). Low operational costs can be achieved through exploiting other means of product promotion like social media, having a flat organisation structure, superior information system and efficient use of capital. With quality customer service, existing customers become loyal to the organization and spread the good news by word of mouth. By doing so, more customers are attracted to a firm without any advertisement cost. In this way, a lot is saved as no promotion costs are incurred.

\subsection{Capability}

A firms' competitive advantage is largely dependent on the ability of the organization to transform its resources in a way that enables it to be a leader in the market. This view gives an understanding of how a firm can transform its resources to gain a competitive advantage (Liqin Ren, Guangya Xie, Koos Krabbendam, 2009) According to the resource based view a firm needs to possess resources that are valuable, scarce, and inimitable and can hardly be replaced .A competitive advantage needs to be hard to be imitated by competitors. This is possible if the competitors hardly understands the source and cannot duplicate both the relevant components of the human resource capital pool and the circumstances under which these resources work.

\subsection{Positive reputation}

The image of a firm to outsiders in terms of its reputation has been described as a source of sustainable competitive advantage (Porter, 1980) Customers tend to cross over between markets as a result of reputation and brand identification. Positive firm reputation can be thought as of informal social relations between firms and key stakeholders who are thought to be socially complex and thus imperfectly inimitable. Research has not clearly stated whether guaranties and positive reputation are substitutes or not. However other firms do invest in both and therefore if the two are not substitutes then positive reputation that is rare and perfectly imitable may be a source of competitive advantage.

\subsection{Learning Organisation}

The central feature of the learning organization is its commitment to seeking and using feedback for development. Learning organization encourages its members to improve their personal skills and qualities, so that they can learn and develop. They benefit from their own and other people's experience, whether it be positive or negative. As more people in every level of a company engage in continual learning a valid contribution can come from any member of the company, and from any part of the company. Being innovative and creative is the responsibility of the whole workforce and allows learning organisations to adapt to changes in the state of the market, technology and competition efficiently. This adaptation to the dynamic nature of business environment, keeps a firm in the forefront thus a source of competitive advantage

Moreover, this creativity gives rise to an increased synergy. The interaction between high performing teams produces a result which is higher than was planned or expected of them.

When a firm is in a position to broaden learning opportunities due to diversity of operating environments it is able to be competitive with other firms

\section{Strategic planning and sustained competitive advantage}

According to Anthony"Strategic planning is the process of deciding on the goals of the organization and the strategies for attaining these goals." Some literature do show the inability of strategic planning 
processes to be in a position to develop a sustained competitive advantage.(Pearce, Freeman, \&Robinson 1987)However, evaluation of strategic planning as a firm resource can help solve these conflicting results. Strategic planning systems cannot on their own be a source of competitive advantage no matter how valuable they are since most firms engage in that activity and in such is not rare. Therefore, any firm interested on engaging in formal planning can certainly do so and in such it seems to be highly imitable (Barney 1989).

Formal strategic planning process should enable a firm to recognise and exploit its resources since these resources could be the source of sustained competitive advantage. Firms can as well develop strategies through emergent processes (Mintsberg, 1978). To the extent that these processes suggest valuable strategies for firms, they can be thought of firm resources and their potential for generating sustained competitive advantage can be evaluated by considering how rare, imperfectly imitable and sustainable they are.

Informal strategies have been considered rare and not easy to imitate but research has shown that firms do prevent these informal processes from unfolding or ignore the strategic insights they generate. (Burgelman $\&$ Maidique, 1988). However firms that understand the potential value of informal strategic processes have been deemed to have a rare strategic resource.

Developing strategy concerns availability of financial resources, keeping in line with emerging trends in technology, the fear and risk of inflation, customer retention as a result of new product development from competing firms and talent retention in human resources. These may be said to be problems associated with developing future strategies.

\section{Resource based approach to sustainable competitive advantage}

Resource based approach to sustainable competitive advantage focuses on the internal analysis of a firm. The approach entails an audit of tangible assets of a company which may be physical, human and financial resources. The audit also entails intangible assets such as brands and patents. Patents and proprietary knowledge serve to restrict entry into an industry. Ideas and knowledge that provide competitive advantages are treated as private property when patented, preventing others from using the knowledge and thus creating a barrier to entry.

Internal analysis aims to identify strengths and weaknesses in a firm. It helps to identify what is achievable and what issues to address.

A firm's strengths are its resources and capabilities that can be used as a basis for developing a competitive advantage. Strengths can be either tangible or intangible. These are what you are well-versed in or what you have expertise in, the traits and qualities your employees possess (individually and as a team) and the distinct features that give your organization its consistency.

Strengths are the beneficial aspects of the organization or the capabilities of an organization, which includes human competencies, process capabilities, financial resources, products and services, customer goodwill and brand loyalty. Examples of organizational strengths are huge financial resources, broad product line, no debt, committed employees, patents, strong brand names, good reputation among customers, cost advantages from proprietary know-how, exclusive access to high grade natural resources, and favorable access to distribution networks.

Weaknesses are the qualities that prevent us from accomplishing our mission and achieving our full potential. The absence of certain strengths may be viewed as a weakness. These weaknesses deteriorate influences on the organizational success and growth. Weaknesses are the factors which do not meet the standards we feel they should meet. Weaknesses in an organization may be depreciating machinery, insufficient research and development facilities, narrow product range, poor decision-making, etc. Weaknesses are controllable. They must be minimized and eliminated. For instance - to overcome obsolete machinery, new machinery can be purchased. Other examples of organizational weaknesses are huge debts, high employee turnover, complex decision making process, narrow product range, large wastage of raw materials, lack of patent protection, a weak brand name, poor reputation among customers, high cost structure, lack of access to the best natural resources, lack of access to key distribution channels, etc In some cases, a weakness may be the flip side of a strength. Take the case in which a firm has a large amount of manufacturing capacity. While this capacity may be considered a strength that competitors do not share, it also may be a considered a weakness if the large investment in manufacturing capacity prevents the firm from reacting quickly to changes in the strategic environment.

Internal analysis should also encompass and fit into the vision, mission, aims and objectives of a firm. It should also help in identifying a series of strategic options the company can consider and form informed choices 


\section{The Value Chain}

Value chain was first suggested by Michael Porter (1985) to depict how customer value accumulates along a chain of activities that lead to the end product or service.

To analyze the specific activities through which firms can create a competitive advantage, it is useful to model the firm as a chain of value-creating activities. Michael Porter identified a set of interrelated generic activities common to a wide range of firms. The resulting model is known as the value chain

\section{Primary Value Chain Activities}

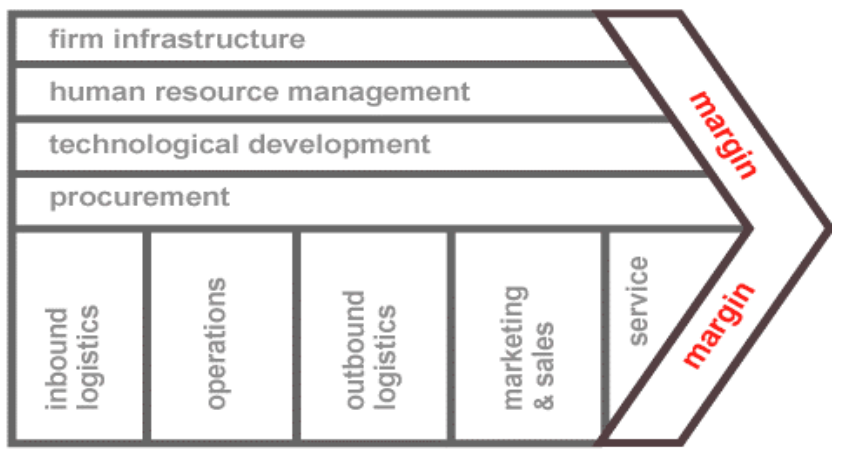

Source (Porter, 1985)

The goal of these activities is to create value that exceeds the cost of providing the product or service, thus generating a profit margin (Porter,1985)

- Inbound logistics include the receiving, warehousing, and inventory control of input materials.

- Operations are the value-creating activities that transform the inputs into the final product.

- Outbound logistics are the activities required to get the finished product to the customer, including warehousing, order fulfillment, etc.

- Marketing \& Sales are those activities associated with getting buyers to purchase the product, including channel selection, advertising, pricing, etc.

- Service activities are those that maintain and enhance the product's value including customer support, repair services, etc.

Any or all of these primary activities may be vital in developing a competitive advantage. For example, logistics activities are critical for a provider of distribution services, and service activities may be the key focus for a firm offering on-site maintenance contracts for office equipment.

\section{Human resources as a firm's resource}

Human resource is the availability of skills, talent and know-how of employees that is required to perform the everyday tasks that are required by the firm's strategy. It is the value that the employees of a business provide through the application of skills, know-how and expertise. Human resource is an organization's combined human capability for solving business problems. Human resource is inherent in people and cannot be owned by an organization. Therefore, it can leave an organization when people leave it also encompasses how effectively an organization uses its people resources as measured by creativity and innovation.

Strategies are implemented through employee behavior, although the employees must possess the competencies needed to portray their behavior

A new perspective of the Human Resource; unlike the previous years, the human resource is now considered as the firm's most valuable resource. Without competent people both in managerial and employee positions, organizations will not be able to accomplish their goals. This means that the firm will not be on a competitive edge with other firms

An efficient policy ensures that only the minimum number of human resource is maintained thus eliminating unnecessary duplication of effort and cutting of wage cost. Human resources are a source of sustained competitive advantage since they are valuable, rare, inimitable and non substitutable

\section{Methodology and Research Design}

The study was largely of a secondary research which relied on secondary data from mainstream banks. Secondary data was obtained from the annual prospectus of mainstream banks. More secondary data was obtained from news lines, bank agent, banks' pamphlets, and research findings from similar studies obtained from libraries, newspapers and other publications. 


\section{Discussions}

An analysis of available literature on sustainability of competitive advantage identifies the following factors as the major challenges in creating competitive advantage in the banking industry.

Banks in Kenya are highly innovative due to the competitive market environment. However, one of the biggest challenge is that, a new bank product can be copied by a competitor. It is therefore hard for a bank to use a new product to gain a sustainable competitive advantage KCB launched agent banking but before the service had rolled properly into the market, competitors immediately introduced the same service and eventually overtook KCB Bank Group.

As much as a sustainable competitive advantage can be gained through launching of new innovative products, there is need to ensure that the process of rolling out the product is properly pre-planned to cater for any unexpected events that can occur during the process. KCB Bank Group has always been facing major challenges after launching a new product. There is need to be proactive by accessing the challenges likely to be faced in the process and how to tackle them when they occur. This will enable in ensuring that a new product does fit the market niche it was intended for.

The presence of competing strategic priorities is also a major challenge according to a research carried out by Accenture (2010). Growth strategy has been the major focus for banks. However this strategy is undertaken without putting into account the impact that a sustainable competitive advantage can have in achieving the overall growth. The subject has been to a large extend not been considered.

Retaining the best tent in an organisations also a way of gaining a competitive edge in the market. However, Banks in Kenya are known to poach from one another through giving competitive packages that attract the high profile people. As much as these talented persons are resourceful to the firm, they are at times left to leave without any proper negotiations. This leads to transfer of insider information from one bank to the other thus making it hard for confidential information meant to give a sustainable competitive advantage to be leaked to competitors.

Proper identification of customers, base of customer loyalty and proper training of employees on customer service is very important. Carrying out of market intelligence is required so as to know what the competitor is currently planning to do or has already done in order to take the right action on time.

\section{Conclusion}

Companies need to overcome change inertia for them to remain competitive. As much as protection of competitive advantages is important, there is need to also exploit new opportunities that come along for the firm to remain competitive over a long period of time. IBM is one of the companies that launched computer technology but its success over time has been undesirable. This is due to the fact that it had concentrated on the protection of old product mainframe other than exploring emerging opportunities. KCB though still competitive changed its approach in banking as a result of entry of new banks in the industry. Its brand name remains its competitive advantage and it's the actions of competitors that made it improve its services. However the biggest challenge is that new banks are always in the forefront in launching new technologies despite its large asset base. As much as a company becomes committed to its core competencies, there is need to as well change direction and foresee changes in technology and the environment (Ning, 2013)

Finally, sustainability of a competitive advantage does not mean that it will last forever but instead it implies that it will not be lost through duplication efforts of others. Thus companies need to exploit all sources of competitive advantage in order to create a unique strategic. Since competitive advantage do have a life cycle, it is important to have a well planned selection and allocation of resources.

\section{Recommendations}

The following are some of the recommendations on how to overcome the challenges of creating a sustainable competitive advantage in the banking sector

There is need to embrace organization learning which is the sum total of individual and collective learning through trainings, experimentation and work interactions within the organization. This is because, whereas single instances of organization learning are easy to imitate, continuous organization learning has cumulative effects that are much more difficult to imitate. Organisation learning leads to knowledge acquisition, distribution, application and translation into organization memory.

It is also important to engage in efficient management of personnel since there is a growing belief that one of the major sources of competitive advantage is the efficient management and development of people. This is due to the fact that it inevitably leads to considerations of diversity which eventually leads to development of practices that balance with global competitiveness. There is need to impact knowledge on middle and senior level managers.

Effective customer relationship management in the the banking sector has been sought as one the ways of attaining a competitive advantage. This is because, CRM strategies enables a bank to create superior value for 
its customers and more profits for self. There is need to give quality service and empathize with the customers. This will result in satisfied customers, repeated purchases and more referrals which will bring in new customers.

Banks can embrace the use of tacit knowledge that has been sought as an imitable source of competitive advantage. It is attained through experience in an activity by observing how experts address problems and receive feedback. However, this can be achieved through the creation of a knowledge sharing culture in the bank, managers couching those that they supervise and motivation by a firms reward system.

Research and development is critical as it creates a means of being market leaders since it helps in keeping up with the changing dynamics in the market. Efficient ways of doing business are being rolled out through R\&D which translated to low cost of operations which is also a source of sustainable competitive advantage.

\section{References}

[1]. Accenture, Top Ten Challenges for Investment Banks: No. 6, Taking Sustainability Seriously (2010)

[2]. Accenture, 'Customer 2012: Time for a new contract between banks and their customers?'

[3]. Andrew Cameron. (2011). A sustainable workplace - we're all in it together. Strategic Direction, 28(1), 3-5

[4]. Barney, J. (1991). Firm Resources and Sustained Competitive advantage. Journal of Management, 17, 99- 120

[5]. Barney, J.,\&Tyler, B.(1991). The perspective limits and potential for applying strategic management theory. Management and Decision Economics

[6]. Christopher Heywood, \& Russell Kenley. (2008). The sustainable competitive advantage model for corporate realestate. Journal of Corporate Real Estate, 10(2), 85-109.

[7]. http://www.lloydsbankinggroup.com/community/environment.asp

[8]. Porter ME (1991). Towards a dynamic theory of strategy. Strategy. Manage. J. 12:95-117. 